\title{
Professores de História e a internet nas escolas: concepções e caminhos
}

\author{
History teachers and the internet in schools: concepts and ways
}

Joelci Mora Silva*

Sônia da Cunha Urt**

\section{Resumo}

Este artigo baseia-se na investigação realizada com professores de História de escolas da rede pública da cidade de Campo Grande (MS). A partir dos levantados em entrevistas, discute-se a inserção das redes sociais on-line no fazer docente. Seus principais objetivos são o estudo e a reflexão acerca dos caminhos do ensino de História em sua interlocução com o uso escolar da internet. As análises e discussões estão balizadas pelos postulados da Teoria Histórico-Cultural e pelas contribuições de estudiosos do ensino de História e das tecnologias digitais. Como resultado, destaca-se que, apesar dos problemas, os professores veem de forma positiva o uso da internet em suas aulas. Conclui-se que é grande o potencial contributivo do uso escolar da internet na produção do conhecimento histórico.

Palavras-chave: ensino de História; internet na escola; Teoria Histórico-Cultural.

\begin{abstract}
The survey with history teachers, of public schools in the city of Campo Grande (MS), is the basis of this article and from its data discusses the inclusion of online social networks on the teaching practice. It has as main objectives the study and reflection of the history's teaching paths in their dialogue with the educational use of the internet. Were used to collect the data interviews. The analysis and discussions based on the postulates of the Historical-cultural Theory, and on contributions of history teaching scholars and digital technologies. As a result, it is emphasized that, despite the problems, the teachers see positively the internet in their classes. It concludes that internet in school use has a large and potential contribution to the production of historical knowledge. Keywords: History teaching; internet in school; Historical-cultural Theory.
\end{abstract}

\footnotetext{
* Doutoranda, Programa de Pós-Graduação em Educação, Universidade Federal de Mato Grosso do Sul (UFMS). Bolsista CAPES. Campo Grande, MS, Brasil. joelci.mora@gmail.com

** Doutora em Educação. Professora Titular, Programa de Pós-Graduação em Educação e Programa de Pós-Graduação em Psicologia, UFMS. Coordenadora do GEPPE - Grupo de Estudos e Pesquisas em Psicologia e Educação da Fundação Universidade Federal de Mato Grosso do Sul (UFMS). Campo Grande, MS, Brasil.surt@terra.com.br
} 
As reflexões que serão apresentadas neste artigo nasceram no ano de 2008, nas pesquisas para a elaboração do trabalho de conclusão de curso (TCC) de um curso de Licenciatura em História. ${ }^{1}$ Havíamos escolhido História Regional como tema de pesquisa e pretendíamos conhecer as concepções dos professores de História de uma escola pública localizada na área central da cidade de Campo Grande (MS) a respeito dos livros didáticos de História Regional. Nas primeiras aproximações com a direção e a coordenação da escola, descobrimos de pronto que, apesar de o uso da internet como fonte de temas e como subsídio para elaboração de aulas ser conteúdo oficialmente inserido no currículo das escolas do estado de Mato Grosso do Sul, não havia nenhum material didático de referência para os professores de História. Desse fato surgiu a necessidade de se conhecer um pouco mais sobre a utilização da internet como recurso didático e, mais do que isso, gerou o seguinte questionamento: qual seria o lugar da internet no ensino de História?

Esse questionamento ganhou força durante o período de docência da disciplina Prática de Ensino em História, no curso de Licenciatura em História da Universidade Federal de Mato Grosso do Sul. Pelas experiências trocadas com os acadêmicos em sala de aula, percebemos como era forte a penetração da internet no cotidiano deles, sendo usada como fonte para o estudo das disciplinas do curso e também para a preparação das aulas por eles ministradas durante o Estágio de Docência.

Tal inquietação transformou-se no problema da pesquisa para elaboração de uma dissertação de mestrado, ${ }^{2}$ que investigou as concepções de professores de História referentes ao uso escolar da internet em suas aulas. São esses olhares que embasaram e incitaram as argumentações que aqui tomarão lugar, permitindo a discussão de algumas situações e possibilidades relacionadas ao uso escolar da internet como ferramenta de apoio ao trabalho docente para a construção do conhecimento histórico.

Temos como escopo deste trabalho o estudo e a reflexão sobre os caminhos do ensino de História em sua interlocução com o uso escolar da internet. De modo que, para alcançá-lo, realizamos uma aproximação pontual entre o percurso do ensino de História no Brasil e a inserção das tecnologias de informação e comunicação no universo escolar.

Após a apresentação dos dados obtidos na fase de campo da pesquisa, buscamos discutir os olhares dos professores de História sobre o uso da 
internet em suas aulas, sua influência no processo de aprendizagem. Em seguida, partindo do apontamento de problemas, vantagens e sugestões, mapeamos algumas possibilidades de caminho para esse binômio.

\section{O ENSINO DA DISCIPLINA DE HISTÓRIA}

\section{E A INTERNET: REFLEXÕES INICIAIS}

A construção dos saberes históricos, bem como o ensino da disciplina de História, passam por constantes transformações que contribuem com alterações significativas tanto nos métodos quanto nos conteúdos ensinados. Como consequência direta disso, observamos a mudança das perspectivas de alunos e professores quanto às práticas adotadas nas aulas, tornando-se necessário, e cada vez mais urgente, a aproximação entre as práticas adotadas na escola e os estímulos multimídia presentes na sociedade contemporânea.

Tais transformações são notórias ao revisitarmos a história do ensino de História no Brasil, desde sua instituição no de ano 1838 como disciplina escolar (Nadai, 1993) até os dias atuais. Ao considerarmos tal processo sob a perspectiva aqui em questão, podemos observar que, ao longo dos anos, deslocaram-se paulatinamente o foco e o escopo definidores da relação ensinar-aprender História.

Em linhas gerais, podemos pontuar que o ensino escolar da História na educação básica passou no Brasil de uma abordagem eurocêntrica - segundo a qual se entendia que esse ensino se restringia a datas e "heróis" - para, nos anos posteriores, instituir-se como disciplina que pretende despertar o senso crítico em seus alunos, além de contribuir para a constituição de sua "identidade coletiva" (Bittencourt, 2004a, p.27), a partir do conhecimento de características de outras sociedades.

Entendemos que tais modificações são reflexos dos momentos sociais vividos, descerram e consolidam os interesses e as ideologias de determinados grupos (Fonseca, 2003). Pode-se citar como exemplo uma das funções da disciplina de História nos anos que sucederam a proclamação da República, quando esteve a serviço da tentativa de consolidação de uma identidade nacional. Ou então quando houve uma tentativa de descaracterizá-la por completo, censurando-se seu aspecto crítico para se atender aos planos da ditadura pós-1964. 
Contudo, cada uma dessas alterações, ainda que refletissem as conveniências desses grupos, acabaram por dar nova forma às relações de ensino e de aprendizagem, determinando outros caminhos e métodos para o ensino de História. Considerando esse aspecto, podemos dizer que saímos do entendimento de que ensinar História concentrava-se especialmente em estimular a memorização para nos voltarmos à preocupação contemporânea de "formar um cidadão comum que necessita de ferramentas intelectuais variadas para se situar na sociedade e compreender o mundo físico e social em que vive" (Bittencourt, 2004b, p.47).

Considerando as variáveis políticas e econômicas que influenciaram seus processos de estabelecimento - e ainda influenciam em sua dinâmica de permanência -, esse ânimo para que os alunos sejam estimulados a conhecerem e entenderem o universo no qual estão inseridos, acaba por gerar um ponto de aproximação entre o ensino de História e as tecnologias de informação e comunicação. Afinal é notório que elas hoje compõem o cotidiano de um grande número de pessoas e, por isso, estão sendo cada vez mais inseridas na educação escolar.

A necessidade dessa aproximação tem sido apontada em documentos curriculares, tais como os Parâmetros Curriculares Nacionais (PCN) para o Ensino Fundamental (1997), nos quais a utilização das diferentes linguagens e recursos é prevista e estimulada para todas as disciplinas, preconizando que o aluno deve "saber utilizar diferentes fontes de informação e recursos tecnológicos para adquirir e construir conhecimentos" (Brasil, 1997, p.5).

Podemos entender a disseminação desses recursos no universo da educação escolar no Brasil, ao considerarmos a reconfiguração tecnológica da maioria dos setores da sociedade, tais como emprego, saúde, lazer, política e educação. Nesse aspecto, concordando com Selwyn (2008, p.817), poderíamos dizer que:

Os fluxos globais de dados, serviços e pessoas, que caracterizam a economia mundial do conhecimento, são sustentados pelas tecnologias da informação e da comunicação (TIC). Do comércio eletrônico (e-commerce) ao aprendizado eletrônico (e-learning), as TIC, como a internet e outros sistemas de telecomunicações mundiais, são os principais canais através dos quais a sociedade contemporânea é encenada. 
Por conta dessa influência e partindo de análises referentes às vantagens que a internet poderia trazer para a área educacional, em 1997 o Ministério da Ciência e da Tecnologia lançou o projeto "Internet na Escola", no intuito de assegurar a instalação de computadores ligados à rede nas escolas públicas do ensino básico e secundário. A partir das ações ligadas a esse projeto, o fenômeno da inserção da internet na educação escolar no Brasil cresceu de forma significativa, totalizando 1.186 .468 equipamentos, em escolas públicas de educação básica, usados exclusivamente por alunos e alunas, de acordo com o Censo Escolar Inep de 2014.

Entendemos a internet na Educação escolar como um recurso capaz de disponibilizar um grande número de possibilidades para novas aprendizagens, permitindo a troca de diversos olhares através da interação pessoal e o contato com variadas mídias. Acerca de suas potencialidades, concordamos com a afirmação de Gadotti (2000, p.7) segundo a qual: "pela internet, a partir de qualquer sala de aula do planeta, pode-se acessar inúmeras bibliotecas em muitas partes do mundo. As novas tecnologias permitem acessar conhecimentos transmitidos não apenas por palavras, mas também por imagens, sons, fotos, vídeos (hipermídia) etc.”.

Vemos, portanto, na internet uma outra maneira de se realizar a interação entre professor, aluno e conhecimento histórico: uma que, pela diversidade de aplicações oferecidas, pode despertar um renovado interesse acerca do tema apresentado. Afinal, além de permitir uma maior aproximação dos envolvidos, a rede disponibiliza algumas experiências que dificilmente aconteceriam longe do mundo virtual, como por exemplo o Giza3D. ${ }^{3}$

Consideramos assim que a internet se perfaz como um objeto provocador que pode contribuir com a elaboração do conhecimento escolar, já que as condições próprias do universo em redes digitais possibilitam a ampliação das interações pessoais, que, por sua vez, estimulam a aprendizagem.

O conhecimento escolar necessita da divisão e das especificidades de cada disciplina para ser produzido, pois ele não pode ser entendido de forma unificada. Como forma de seleção, transmissão e apropriação de saberes já constituídos, ele só pode ser compreendido por intermédio de "processos de transposição (mediação) didática e de disciplinarização, eminentemente constitutivos de configurações cognitivas próprias" (Lopes, 1999, p.24).

Nesse sentido, entendemos que o conhecimento histórico escolar 
é uma forma de saber que pressupõe um método científico no processo de transposição da ciência de referência para uma situação de ensino, permeando-se, em sua reelaboração, com o conhecimento proveniente do 'senso comum', de representações sociais de professores e alunos que são redefinidos de forma dinâmica e contínua na sala de aula. (Bittencourt, 2004, p.25)

No tocante à (re)elaboração do conhecimento histórico escolar, concordamos com Fonseca (2010) quando escreve que todos os veículos de comunicação de massa, tais como TV, livros, jornais, revistas, cinema, foto, música, a internet, espaços virtuais, monumentos, documentos orais e impressos, entre outros, são fontes para o ensino de História e "contribuem para a produção e difusão do conhecimento responsáveis pela formação do pensamento crítico" (Fonseca, 2010, p.10).

Aqui nos interessa especialmente tratar da internet como uma ferramenta tecnológica para uso presencial, com potencial para auxiliar no ensino de História, possibilitando contato com diversas fontes históricas, acesso a pesquisas e a espaços virtuais significativos e específicos da área de História, além de facilitar a comunicação e a interação entre estudiosos e pessoas interessadas por essa ciência.

Ainda que tenhamos apontado as questões incentivadoras a seu uso, não poderíamos encerrar essas reflexões iniciais sem destacar alguns contrapontos e entraves para o uso escolar da internet na disciplina de História, tais como: as formações inicial e continuada dos docentes, que não contam com uma articulação específica entre internet e os saberes históricos; a carga horária reduzida da disciplina que não estimula e, por vezes, inviabiliza o uso de ferramentas de apoio ao trabalho do docente; o tempo limitado de trabalho efetivo na sala de informática e as próprias condições dos computadores disponíveis nessa sala. Todos esses são fatores que desmotivam os professores de História a organizarem projetos e trabalhos com a internet, implicando portanto dificuldades na criação ativa de conhecimento e participação colaborativa (Selwyn, 2011) e, por vezes, falta de uma comprovação da efetividade de sua contribuição para aprendizagem (Dwyer et al., 2007), dentre outros problemas.

Por todos esses motivos, tornou-se fundamental conhecer a visão que os professores da disciplina de História possuíam sobre a utilização da internet em suas aulas, o que foi possível fazer pesquisando sobre como os saberes 
históricos são trabalhados e como são percebidos os resultados da interlocução internet versus História. Preocupou-nos, especialmente, verificar, por intermédio da percepção desses professores, se o uso da internet de fato colabora para a produção do conhecimento histórico escolar de seus alunos.

\section{O USO ESCOLAR DA INTERNET E OS CAMINHOS DO ENSINO DE História: CONCEPÇÕES DOS PROFESSORES}

Terá lugar aqui a pormenorização dos passos percorridos para a realização da fase de campo da pesquisa, composta pela coleta e posterior análise dos dados obtidos por meio das respostas dadas pelos professores colaboradores. Tais resultados comporão nossa discussão teórica, que será realizada sob os postulados da Teoria Histórico-Cultural, também considerando as assertivas de estudiosos das áreas de ensino de História e das tecnologias na educação.

\section{A pesquisa}

Tendo como objetivo principal conhecer as concepções dos professores de História referentes às questões do uso escolar da internet, procedemos às investigações da fase de estudo de campo que compuseram a parte central da nossa dissertação de mestrado intitulada "O 'internetismo' escolar e os processos educativos: percepções dos professores”.

Contamos com a colaboração de quatro professores voluntários (quadro 1) que lecionavam em diferentes escolas públicas na cidade de Campo Grande (MS) e que atendiam aos seguintes critérios predefinidos: ter idade igual ou superior a 18 anos; possuir dois anos ou mais de experiência lecionando a disciplina de História; ter feito uso da internet em suas atividades docentes pelo menos durante um ano letivo em escolas públicas.

Partimos da questão principal "Como os professores de História veem a internet nos processos educativos" e, para conhecermos os olhares desses docentes, lançamos mão de dois instrumentos de coleta de dados. Realizamos, no primeiro momento, entrevistas semiestruturadas, que foram gravadas e posteriormente transcritas. Em uma segunda etapa, consideramos os comentários de um exercício que consistia em interpretação de imagens, resolvidos 
e postados em um blogue especificamente desenvolvido para esse fim. Essa coleta de dados ocorreu entre os meses de setembro e outubro de 2010.

Quadro 1 - Perfil dos professores participantes

\begin{tabular}{|c|c|c|c|c|c|c|c|c|c|}
\hline & $\begin{array}{c}\text { Ano } \\
\text { grad. }\end{array}$ & Curso & Idade & IES & $\begin{array}{c}\text { Pós- } \\
\text { Grad. }\end{array}$ & Rede & $\begin{array}{c}\text { Séries em } \\
\text { que leciona }\end{array}$ & Sexo & $\begin{array}{c}\text { Anos que } \\
\text { leciona } \\
\text { História }\end{array}$ \\
\hline Prof1 & 2006 & Hist.-Licenc. & 40 & UFMS & Não & $\begin{array}{c}\text { Estad. } \\
\text { Munic. }\end{array}$ & $1^{\circ}$ ao $3^{\circ} \mathrm{EM}$ & $\mathrm{F}$ & 4 \\
\hline Prof2 & 2008 & Hist.-Licenc. & 24 & UCDB & Não & $\begin{array}{c}\text { Estad. } \\
\text { Munic. }\end{array}$ & $\begin{array}{c}5^{\circ} \text { ao } 9^{\circ} \mathrm{EF} \\
1^{\circ} \text { ao } 3^{\circ} \mathrm{EM}\end{array}$ & $\mathrm{M}$ & 2 \\
\hline Prof3 & 2006 & C. Sociais & 28 & UFMS & Não & Estad. & $5^{\circ}$ ao $9^{\circ} \mathrm{EF}$ & $\mathrm{M}$ & 4 \\
\hline Prof4 & 2002 & Hist.-Licenc. & 30 & UCDB & Não & Estad. & $1^{\circ}$ ao $3^{\circ} \mathrm{EM}$ & $\mathrm{M}$ & 7 \\
\hline
\end{tabular}

Organizado pelas autoras; Legenda: EF - Ensino Fundamental; EM - Ensino Médio

Através da técnica de análise de conteúdo aplicada às respostas obtidas, depreenderam-se cinco categorias: ferramenta de apoio; aprendizagem e conhecimento; estrutura deficitária; centrada na informação e falta de preparo. A seguir explicamos a constituição de cada uma das categorias de análise, com o objetivo de possibilitar um melhor entendimento dos resultados obtidos:

Respostas que indicavam a internet especialmente como uma ferramenta de apoio para as atividades docentes compuseram a categoria "Ferramenta de apoio".

A categoria "Aprendizagem e conhecimento" foi formada a partir das respostas que indicavam que, apesar de todos os contratempos, a internet ainda era um contributo à aprendizagem e ao conhecimento.

Identificamos recorrentes reclamações contra a estrutura de funcionamento das salas de informática por parte dos professores entrevistados, como, por exemplo, falhas nas definições de horário para uso das salas de tecnologia, manutenção dos equipamentos, número de computadores insuficiente, dependência do profissional da sala de informática etc. Dada a importância de tais colocações, constituímos, a partir delas, a categoria "Estrutura deficitária".

Compuseram a categoria "Centrada na informação" as impressões dos professores que sinalizavam o alto potencial de disponibilização de 
informações que a internet possui. Tais impressões continham críticas e reflexões relacionadas à credibilidade das informações disponíveis.

Em suas respostas os professores revelaram especial preocupação com a questão da falta de preparo para a utilização da internet e seus serviços em suas aulas. Tal entendimento aplica-se tanto a professores quanto aos alunos na visão de alguns participantes, e faz pensar tanto em falta de formação docente quanto em desconhecimento dos alunos quanto às aplicações educacionais da rede.

Com a finalidade de explicitar a incidência das respostas separadas por categoria, organizamos o Gráfico 1, exposto a seguir. Esses dados permitem uma visualização geral de quais as concepções dominantes verificadas nas respostas dadas pelos professores.

Gráfico 1 - Incidências das concepções por categoria

Percentuais das respostas por categoria

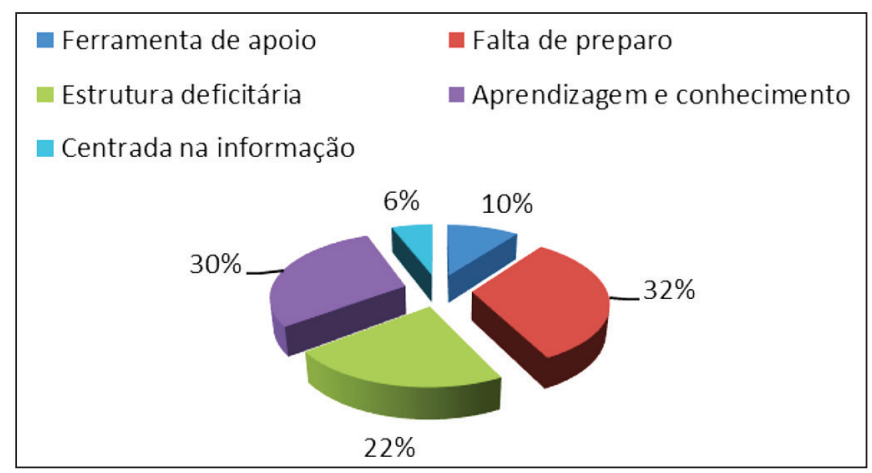

Organizado pelas autoras.

Uma das questões inquietantes, sempre presente nos debates sobre os caminhos da História ensinada nas escolas, é a necessária articulação entre o passado e o presente na formação da consciência histórica dos alunos. Nesse sentido, concordamos com Rüsen (2006) quando ele sugere que tal consciência não pode ser entendida apenas como o conhecimento do passado, já que é responsável pela "estruturação do conhecimento histórico, abrigando uma complexa reunião, efetivada pela apreensão do passado, despertada por uma necessidade de entender o presente e antecipar o futuro" (Rüsen, 2006, p.14). 
Por essa dinâmica, o aluno conseguirá interpretar dados da historiografia, entendendo seus significados e atribuindo-lhes sentidos (Vigotski, 2001) que colaborarão para a aprendizagem, desenvolvendo a atenção voluntária, a percepção, a memória e o pensamento abstrato (Vygotsky, 2000).

A seguir, terão lugar as análises e discussões das considerações que destacaram a utilização escolar da internet no ensino de História e que contemplaram especialmente a relação ensino-aprendizagem e a produção do conhecimento histórico.

\section{Os olhares}

Aqui nos importou discutir especificamente algumas respostas dos professores colaboradores, dadas às questões que evidenciaram os olhares para a relação direta entre o uso da internet e as aulas de História, a saber: "Qual sua opinião sobre o uso da internet para o ensino da disciplina de História?"; "Na sua percepção, houve um crescimento na aprendizagem dos alunos que poderia ser creditado ao uso da internet em sua disciplina? Como isso foi percebido?".

Buscamos, com a primeira pergunta, conhecer aspectos ímpares da aplicação específica dos recursos da internet às aulas de História sujeitos à dinâmica própria dessa disciplina. Foi possível perceber que todos os professores participantes tinham opiniões favoráveis, como mostra o excerto destacado a seguir:

Nós sabemos que o material para a gente, a rede em si, traz muito conteúdo. Eu gosto muito de trabalhar documentários, gosto de passar filmes relacionados com a disciplina, e gosto também de entretê-los, às vezes, com entrevistas, com alguma notícia, que a gente pega da internet e leva pra eles, para ter uma discussão, um "bate-bola", principalmente com as turmas mais adultas. (Prof. 1)

É uma maneira de usá-la como instrumento alternativo para a construção do conhecimento histórico escolar, corroborando o pensamento de que a internet "propicia ao indivíduo interligar-se com o mundo, resultando em escolas mais flexíveis, menos autoritárias, cedendo lugar para ambientes aconchegantes, atrativos, estimuladores e criativos" (Moran, 1997). 
Partindo desse olhar, podemos aqui considerar a questão do papel do ensino de História, ratificando a importância de que, para além da teoria pura, é importante estimular seu aprendizado através da vivência, possibilitando o entendimento do passado sob a luz do presente:

As aulas de História... História é uma disciplina que exige do aluno um conhecimento não só teórico, mas de vivência, porque a história não é uma história do passado e brigamos por uma História do presente. Então a informática é fundamental nesse ponto porque ela passa a ser um elemento de complementação do aluno para entender o seu presente. (Prof. 3)

Tal conhecimento só pode ser promovido através do estímulo ao aluno para que viva experiências que transporão para o universo concreto os saberes históricos que até então possuíam apenas uma existência abstrata. Entendemos que a História "é uma matéria de experiência e interpretação" (Rüsen, 2006, p.16) e, portanto, não pode prescindir desse movimento entre passado e presente para que seja compreendida.

Pelo relato de um dos professores, apresentado a seguir, temos um exemplo das possibilidades da utilização da internet, de maneira a promover uma aproximação do aluno com os saberes ensinados através de um contato concreto com uma fonte histórica:

mas de forma concreta o computador me ajuda muito; por exemplo, eu tenho lá a pré-história, neolítico e paleolítico, então o paleolítico é da pedra lascada, eu posso mostrar um objeto do paleolítico ele vai identificar ali na imagem, e no do neolítico é da pedra polida, então ele identifica a diferença de um período pro outro de forma visual, é uma fonte histórica; na sala de aula acaba sendo muito restrito ao texto só, não fica tão legal. (Prof. 4)

A experiência desse professor põe em prática as possibilidades de uso da internet como uma ferramenta que disponibiliza caminhos e métodos diferenciados para o ensino de História, colocando em evidência o uso de fontes históricas que são, por definição, diversas e abarcam tudo que possa revelar marcas da presença humana e que dela tragam informações (Bloch, 2001, p.79), promovendo, por essa via, uma transposição didática entre o conhecimento científico e o saber que será ensinado. Tal ação 
pode contribuir para a construção da consciência histórica crítica de alunos e professores, considerando-se: a) a relevância do conhecimento histórico, ou seja, do saber a ser ensinado, encontrado nos indícios documentais e na experiência cultural de alunos e professores, em confronto com outras fontes de conhecimento histórico como, por exemplo, os manuais didáticos. (Schmidt; Garcia, 2005, p.304)

Podemos ponderar que a internet se presta a essa ação pela variedade de possibilidades que oferece, sendo uma ferramenta dinâmica e interessante, a qual permite realizar interações entre pessoas e grupos, também facilitando o contato de seus usuários com uma grande quantidade de informações disponíveis.

Sua facilidade de acesso aliada a recursos multimídia disponíveis em aplicações desenvolvidas em uma linguagem visual fácil e chamativa potencializam as possibilidades dessa rede. Tais características acabaram por torná-la agradável, capaz de despertar o interesse e prender a atenção dos alunos, como podemos perceber pelo depoimento do professor:

A aula fica muito mais dinâmica, muito mais. É aquela coisa: hoje nós competimos com o mundo fora da escola, e qual é o mundo que eles vivem fora da escola? Um mundo muito mais dinâmico. Não dá mais para ter aquele giz, caderno e livro; você não vai conseguir prender a atenção do aluno duas horas seguidas, se forem aulas geminadas. Então a aula fica mais dinâmica, ela fica mais visual, ela fica mais sonora, ela fica mais interessante para o aluno. (Prof. 4)

Em que pesem todas essas características, também devemos pontuar que o acesso a fontes históricas não deve ser restrito apenas às informações contidas na internet. Apesar de facilitar e aproximar os alunos de lugares e documentos que possuem o acesso dificultado, essa via não pode ser encarada como única. Isso, sem dúvida, desmotivaria o contato com museus e arquivos que estão ao alcance do aluno e que possibilitam uma experiência mais completa e rica do que um tour virtual. Entendemos que a internet se configura não como única, mas sim como mais uma possibilidade para o ensino de História.

Ao perguntarmos aos professores pesquisados se houve crescimento na aprendizagem em suas aulas com a utilização da internet, as respostas afirmativas foram unânimes, como demonstram os destaques: 
Na maioria das vezes é melhor. É maior o interesse dos alunos. Os alunos se interessam mais por algo que eles consideram mais atual. A História já é algo que passou, na concepção deles. Às vezes alguns não têm a ideia de que a História está sendo construída hoje. Mas eles vendo que dá para utilizar algo atual, tecnológico, moderno numa matéria que para eles, do ponto de vista deles, muitas vezes é ultrapassado, fica bem interessante e aumenta o interesse. Eu acho que é por ai: o interesse traz o atualizá-los. (Prof. 4)

Com certeza, porque, como eu disse a você, eu trabalho com filmes relacionados à minha disciplina e com documentários, e isso acrescenta, maravilhosamente, ao conteúdo. Eu, particularmente, já trabalhei com turmas menores, mas trabalho muito mais com médio e cursinho, e o resultado é fabuloso. $\mathrm{O}$ interesse deles sobre os assuntos citados cresce muito, a aprendizagem corre muito mais. Eu acho que só tem que melhorar. (Prof. 1)

Para Vigotski (2001), a faculdade de pensar estava definitivamente ligada aos sentimentos. Ele defendia que, por essa união, as emoções também estão no centro das questões de aprendizagem e de desenvolvimento intelectual. As emoções são, dessa forma, a causa do pensamento, já que analisá-lo "pressupõe necessariamente a revelação dos motivos, necessidades, interesses, motivações e tendências motrizes do pensamento, que lhe orientam o movimento nesse ou naquele aspecto" (Vigotski, 2001, p.16).

Pelo exposto, podemos entender que os estímulos externos, quando nos causam sentimentos positivos, são capazes de direcionar nosso pensamento, facilitando a internalização das experiências, desenvolvendo a cognição e possibilitando a aprendizagem. Inferimos que esse é o principal motivo para que o excerto destacado acima revele um relato de bons resultados percebidos pela professora na articulação entre ensino de História e internet. Nas palavras de Vigotski (2003, p.149): "Não devemos nos esquecer de atingir o sentimento do aluno quando queremos enraizar alguma coisa na sua mente".

\section{Os caminhos: o que temos e o que queremos}

Existem sérias questões levantadas nesta pesquisa que merecem destaque, tais como a falta de estrutura física em salas com número insuficiente de computadores, número baixo de salas de informática, manutenção inadequada nos equipamentos, falta de preparo dos docentes e dos alunos para uma utilização de fato educacional da rede: 
Quando você consegue esses horários, não é? Na maioria das vezes é difícil. Você leva quase um mês para conseguir agendar um ou dois tempos numa sala de tecnologia ... As salas da rede pública geralmente são com mais de quarenta alunos, então, as salas de tecnologia não comportam e, quando você os leva, geralmente algumas máquinas estão com defeito, não funcionam. (Prof. 1)

Falta, às vezes, conhecimento básico dos alunos, de como navegar na internet, desde como ligar um computador, que é importante, até como entrar no [navegador Internet] Explorer. (Prof. 4)

Ela é tão ampla, ela é tão abrangente em conteúdos, que o aluno se perde. Então a gente tem que ter cuidado nisso. Filtrar o que é possível e o que não é possível, até chegar no que é considerado educativo. (Prof. 3)

Mas do que necessitamos para que bons frutos sejam colhidos nessa relação? Quais os caminhos a percorrer para garantir uma colaboração cada vez maior da internet na construção dos saberes da disciplina de História?

Partimos de problemas apontados para propor reflexões dos possíveis caminhos para a relação entre ensino de História e a utilização da internet na educação escolar. Para fazê-lo, lançamos mão das análises das respostas dos professores para entrevermos possíveis trajetórias para um melhor aproveitamento da internet no ensino de História.

Trouxemos respostas às seguintes indagações: "Quais os problemas e/ou vantagens que o $\operatorname{sr}($ a) percebe na utilização da internet na sua disciplina?"; "Quais as sugestões que o(a) sr(a) daria para um melhor aproveitamento da internet no ensino de História?”.

Dentre as variadas respostas, muitas críticas se concentraram nas questões concernentes à estrutura física deficitária e ao despreparo de professores e alunos para trabalhar com internet. Respostas com essas opiniões foram as mais mencionadas como problemas a serem superados para uma real inserção da internet em suas ações docentes.

Iremos nos concentrar aqui na questão da falta de preparo docente, por entendermos a importância fulcral da ação dos professores em todo e qualquer processo relacionado a ensino e aprendizagem. Nas palavras da professora colaboradora:

É um processo ainda muito turbulento. Muito nebuloso, eu diria, porque ainda precisa de muito estudo, muita concentração nisso. Eu vejo que nem os docentes 
estão preparados para isso e nem os discentes têm segurança, muito menos, já que os docentes não têm uma boa preparação. Por fim, isso chega a eles de uma maneira incorreta. Então, acho que falta muito a percorrer. (Prof. 1)

Acreditamos que devemos nos esforçar para percorrer essa distância que falta, por acreditarmos que o papel do professor é fundamental para a aprendizagem, na exata medida em que cremos que é dele a função de orientar e conduzir a relação entre o conhecimento e o aluno. Temos nos postulados de Vigotski (1988) e de Leontiev (1978) a afirmação do caráter basilar do trabalho do professor no processo de apropriação da herança cultural humana historicamente construída. É dele a escolha e a seleção dos instrumentos que conduzirão as influências socioculturais que influenciarão e provocarão as transformações cognitivas inerentes ao desenvolvimento do sujeito (Vygotsky, 1994).

É necessário que o professor se sinta seguro tanto em relação aos conteúdos que irá trabalhar quanto no que diz respeito às ferramentas de que lançará mão para auxiliá-lo. Para que isso ocorra, é desejável que ele tenha uma formação direcionada aos recursos tecnológicos que pretenda usar, não com o objetivo de dominar totalmente os detalhes de tais recursos, mas para ampliar as possibilidades de seu uso e, principalmente, aplicá-los de forma específica e significativa em suas atividades, articulando-as com as necessidades dos saberes que serão ensinados.

Um dos caminhos para minimizar os efeitos da falta de preparo surgiu da seguinte resposta:

Eu acho que ela deveria se utilizar sim da disciplina de Prática de Ensino, da disciplina de Estágio ... Dentro dessas disciplinas pedagógicas, tentar abarcar essa coisa da informática para facilitar para o futuro professor, ter uma explicação, uma explanação maior. (Prof. 3)

Acreditamos que a presença da informática nas disciplinas pedagógicas das licenciaturas em História tem potencial para contribuir na formação dos docentes dessa disciplina. Essa formação inicial aliada às formações continuadas ampliariam muito as possibilidades de sucesso da articulação entre ensino de História e os recursos acessíveis pela internet. Nesse sentido, concordamos que: 
É necessário voltar o olhar para a formação inicial e contínua dos professores de história, priorizando a prática pedagógica, o fazer historiográfico em comunicação com as novas tecnologias, compreendendo-as como potencializadoras da construção do conhecimento escolar de história de forma a propiciar uma aprendizagem significativa. (França; Simon, 2014, p.193)

Importante destacar que, para lograr êxito, não seria suficiente o ensino de informática básica. O mais necessário seria trazer ao conhecimento do acadêmico às aplicações específicas da área de História que existem em grande número em nossos dias. Ao conhecer programas, aplicações e recursos, entendemos que seria possível reduzir a distância e o estranhamento de alguns com relação aos recursos de informática. Para além da familiaridade, uma vez conhecidos tais recursos disponíveis para compor suas aulas, eles passariam a fazer parte do instrumental de domínio desses professores em formação, se assim o quisessem. Existem muitas possibilidades para a utilização da internet e a seguir discutiremos uma delas: as redes sociais.

\section{Redes sociais on-line e o ensino de História: uma aproximação possível}

Um dos fatores que habilitam, ao nosso entender, as redes sociais on-line para sua inserção na educação escolar é sua expressiva participação no dia a dia de um número cada vez maior de pessoas. Essa característica diminui muito a resistência inicial observada na proposição de novas abordagens na área de informática.

Em outra análise, podemos perceber que a relação que as pessoas têm com a informação e com o saber vem se alterando com o passar dos anos, e as redes sociais on-line têm possibilitado um nível de interação pessoal inimaginável até poucos anos atrás. Concordando com Pierre Lévy, quando trata das mudanças na relação com o conhecimento provocadas pela cibercultura (1999), podemos entender que: "O uso crescente das tecnologias digitais e das redes de comunicação interativas está acompanhando e ampliando uma profunda mutação da relação com o saber" (Lévy, 1999, p.11).

Esses novos rumos do saber fazem crescer a necessidade de se acompanhar de perto seus desdobramentos, para que possamos compreender com que intensidade a educação escolar sofreu impacto das interferências do uso das redes sociais on-line nos processos de aprendizagem que se desenrolam em seus 
espaços. Essa mudança acabou por emprestar às redes sociais on-line o potencial de ambiente de mediação virtual, onde um outro tipo de comunicação e interação pode ser experimentado, modificando assim as relações antes postas. Ou, nas palavras de Marco Silva (2001, p.15): "Mais do que nunca o professor está desafiado a modificar sua comunicação em sala de aula e na educação. Isso significa modificar sua autoria enquanto docente e inventar um novo modelo de educação ... A época é essa!: a era digital, a sociedade em rede, a sociedade de informação, a cibercultura".

Como um exemplo especificamente ligado ao ensino de História, gostaríamos de destacar a rede social "Café história” (http://cafehistoria.ning.com/). Essa rede foi criada em janeiro de 2008 pelo jornalista e historiador Bruno Leal e tem como público alvo os estudantes, professores, pesquisadores. É também dedicada, como está escrito no item "quem somos" na apresentação da página: "para todos aqueles que acreditam que estudar e discutir história é o maior barato". Essa rede conta com 60.389 membros cadastrados, mas o seu conteúdo é completamente livre. Nela, as pessoas interessadas participam de fóruns de discussão sobre temas relacionados aos saberes históricos e têm acesso a uma biblioteca on-line em que podem ser encontrados filmes, fotos, livros, textos científicos em geral, links para sites interessantes da área, entre outros recursos.

Além dessa utilização direcionada, o Facebook também tem demonstrado potencial para trocas de assuntos específicos, através de suas fanpages, grupos e aplicativos que podem ser baixados e utilizados em sua página. O uso educacional do Facebook tem sido notado nas relações entre professores e alunos. Os professores utilizam aquele espaço para promover fóruns de discussão, indicar leituras e vídeos. Em grupos fechados, é possível até mesmo o envio de arquivos de atividades.

Essas possibilidades educacionais do Facebook estão sendo pesquisadas e analisadas criticamente, possibilitando reflexões importantes sobre seu real potencial e sobre algumas falsas promessas para as quais devemos dedicar atenção, por isso concordamos que "Enquanto o Facebook, assim como outras plataformas de redes sociais, oferece possibilidades bastante interessantes para a Educação, propõe também muitos desafios às práticas e concepções correntes, tanto de docentes quanto dos próprios alunos" (Ferreira; Bohadan, 2014, p.136). 
Por esses exemplos, podemos verificar as redes sociais sendo usadas como ambiente de mediação em curso, possibilitando trocas e momentos de aprendizagem. Podemos então entender, a partir do exposto, que as redes sociais on-line facilitam o acesso a um espaço que é simultaneamente coletivo e colaborativo, tanto para a comunicação quanto para produção de conhecimento, ao incentivar a pesquisa, permitindo um estudo de forma diferenciada dos assuntos, portanto estimulando fatores desejáveis na aprendizagem (Tomael; Alcara; Di Chiara, 2005; Hessel et al., 2012; Couto Junior, 2012).

Entendemos que, hoje, a internet imersa na educação escolar possa inaugurar mais um caminho para a aprendizagem. Para isso, se faz necessário aperfeiçoar e direcionar sua utilização, levando sempre em conta o leque de possibilidades disponíveis para não perverter seu papel de apoio às ações docentes. Dessa forma ela poderá colaborar com o desenvolvimento cognitivo dos alunos, contribuindo para as atividades mediadas. Por isso concordarmos que:

O uso de meios artificiais - a transição para a atividade mediada - muda, fundamentalmente, todas as operações psicológicas, assim como o uso de instrumentos amplia de forma ilimitada a gama de atividades em cujo interior as novas funções psicológicas podem operar. Nesse contexto, podemos usar a lógica superior, ou comportamento superior com referência à combinação entre o instrumento e o signo na atividade psicológica. (Vygotsky, 1994, p.73)

Talvez consigamos, por intermédio dessa alteração de métodos e saberes, que exigem outros olhares e entendimentos revisitados, voltar cada vez mais nossa atenção para a importante questão do desenvolvimento cognitivo específico possibilitado pelo ensino da disciplina de História, concordando nesse ponto com Bittencourt (2004), quando em seu livro ela vaticina que "as mudanças culturais provocadas pelos meios audiovisuais e pelos computadores são inevitáveis, pois geram sujeitos com novas habilidades e diferentes capacidades de entender o mundo" (p.108).

\section{Algumas considerações}

As especificidades dos estudos para a composição deste artigo nos permitiu revisitar algumas concepções, partindo dos olhares dos professores participantes. Ao longo desse percurso, notamos que elas foram se enriquecendo a cada discussão teórica realizada. 
Entendemos que o uso da internet e de seus serviços não possuem o poder de resolver os problemas vivenciados na educação escolar do Brasil, tampouco os relacionados ao ensino da disciplina de História. A rede não é, como muitos querem crer, a solução de problemas fundamentais encontrados nas escolas, tais como falta de investimento em instalações adequadas, formação adequada dos professores, índice de desistência e repetência, dentre outros. Ao contrário, o sucesso de seu emprego didático só pode ser cogitado em articulação com as soluções desses problemas. Isso se dá porque vemos a internet como ferramenta, que, por essa condição, depende da forma como é usada para lograr êxito.

Também não fazemos coro com o pensamento que afirma que seu uso deve ter caráter obrigatório no fazer docente, sendo visto como garantia de sucesso para os processos escolares de ensino e aprendizagem. O professor, independente da disciplina que leciona, deve ter a prerrogativa de optar ou não por sua escolha. Nesse sentido, o que aqui tentamos fazer foi apontar suas possibilidades de contribuição, sem, de forma alguma, ignorar as dificuldades e desafios para seu uso. Esse foi o direcionamento adotado, ao percebermos que, por mais que os participantes da pesquisa apontassem esses problemas, $\mathrm{o}$ entendimento de que é grande o potencial de contribuição da internet aplicada ao ensino de História foi um posicionamento unânime.

Existe muito a se aprimorar no tocante à forma como a internet está posta nas escolas, uma vez que os estudos realizados até aqui apontaram para a falta de preparo adequado de professores e alunos, bem como estruturas físicas e técnicas deficitárias. Essas questões devem ser repensadas, posto que atrapalham muito a utilização planejada e proveitosa dos recursos da internet.

Ainda na seara da formação, consideramos que seria positiva a presença da disciplina Informática na formação inicial dos futuros professores de História, em virtude da já conhecida utilização desse recurso na maioria das escolas públicas do Brasil. Isso não anularia a importância de também existirem programas de formação continuada, uma vez que a área de informática incorpora novidades com grande velocidade.

Entendemos que o uso escolar da internet, especificamente aplicado à disciplina de História, pode possibilitar adicionalmente outras vivências e experiências aos alunos, contribuindo também para alterar o caráter abstrato de um ensino limitado, percebido na aplicação de alguns métodos tradicionais. Suas contribuições na elaboração do conhecimento histórico escolar estão, 
assim, em promover experiências e incitar interpretações, uma vez que é tida como uma ferramenta cultural contemporânea, presente no dia a dia de um número significativo de alunos e professores, mas que pode colocá-los em contato com outros tempos, por meio de fontes históricas, trazendo a pesquisa histórica para sala de aula, articulando o saber científico com o saber ensinado.

Consideramos também as redes sociais como um ambiente capaz de proporcionar a mediação desse conhecimento, usando suas ferramentas em favor da interação entre professores e alunos, por intermédio de grupos e páginas de interessem possibilitando ademais o acesso a informações em diversos formatos.

Por fim, acreditamos que o estudo da interlocução entre ensino de História e internet inserida em processos educativos escolares merece aprofundamentos e revisitações constantes. Além de reiteradas contribuições críticas, por se tratar de campo novo e importante. Essa disciplina possui um papel fundamental para que o aluno se reconheça como um indivíduo participante da sociedade na qual está inserido, para que compreenda as situações do presente a partir dos processos históricos que as constituíram.

Entendemos que a internet pode colaborar nesse sentido.

\section{REFERÊNCIAS}

BITTENCOURT, Circe Maria Fernandes. Ensino de História: fundamentos e métodos. São Paulo: Cortez, 2004a.

. Capitalismo e cidadania nas atuais propostas curriculares de História. In: BITTENCOURT, Circe Maria Fernandes (Org.) O saber histórico na sala de aula. 9.ed. São Paulo: Contexto, 2004b. p.11-27.

BLOCH, Marc. Apologia da História ou ofício do historiador. Trad. André Telles. Rio de Janeiro: Zahar, 2001.

BRASIL. Secretaria de Educação Fundamental. Parâmetros curriculares nacionais: história, geografia. $1^{\circ}$ ao $4^{\circ}$ anos. - Brasília: MEC/SEF, 1997. Disponível em: http://portal.mec.gov.br/seb/arquivos/pdf/livro051.pdf; Acesso em: 20 jul. 2015.

CORREIA, Franklin Portela. O impacto das redes sociais na profissão docente. Dissertação (Mestrado em Educação) - Faculdade de Humanidades e Direito, Universidade Metodista de São Paulo. São Bernardo do Campo, 2013. Disponível 
em: http://ibict.metodista.br/tedeSimplificado/tde_busca/arquivo.php?cod Arquivo=3410; Acesso em: 8 jan. 2016.

COUTO JUNIOR, Dilton Ribeiro. Cibercultura, juventude e alteridade: aprendendo-ensinando com o outro no Facebook. Dissertação (Mestrado em Educação) - Faculdade de Educação, Universidade do Estado do Rio de Janeiro (Uerj). Rio de Janeiro, 2012. Disponível em: http://www.bdtd.uerj.br/tde_busca/arquivo. php?codArquivo=5396; Acesso em: 8 jan. 2016.

DWYER, Tom et al. Desvendando mitos: os computadores e o desempenho no sistema escolar. Educação \& Sociedade, Campinas, v.28, n.101, p.1303-1328, 2007.

FERREIRA, Giselle Martins dos Santos; BOHADANA, Estrella D'Alva Benaion. O Facebook na educação: um novo sujeito? Educação e Cultura Contemporânea, v.11, p.112-141, 2014.

FONSECA, Selva Guimarães. A História na Educação Básica: conteúdos, abordagens e metodologias. In: SEMINÁRIO NACIONAL: CURRÍCULO EM MOVIMENTO - PERSPECTIVAS ATUAIS, I., 2010, Belo Horizonte. Anais eletrônicos... Disponível em: UFMS/Doutorado\%20Educa\%C3\%A7\%C3\%A3o_2013.2/Livro\%20 Ed\%20Integral\%20PROPOSTA\%20CURRIC/3.4_\%20historia_educacao_basica_ selva.pdf; Acesso em: 20 ago. 2015.

FONSECA, Thais Nívea de Lima. História \& Ensino de História. Belo Horizonte: Autêntica, 2003.

FRANÇA, Cyntia Simioni; SIMON, Cristiano Biazzo. Professores de história: o uso do computador na construção do conhecimento histórico escolar. Tempo e Argumento, v.6, p.186-211, 2014.

GADOTTI, Moacir. Perspectivas atuais da educação. São Paulo em Perspec., São Paulo, v.14, n.2, p.3-11, jun. 2000. Disponível em: http://www.scielo.br/scielo. php? script $=$ sci_arttext\&pid $=$ S0102-88392000000200002\&lng $=$ en $\& \mathrm{nrm}=\mathrm{iso}$; Acesso em: 22 set. 2015.

INEP. Censo Escolar: Infraestrutura - Tecnologia. 2014. Disponível em: http://www. qedu.org.br/brasil/censo-escolar?year $=2014 \&$ dependence $=0$ \&localization $=0 \&$ edu cation_stage $=0$ \&item $=$; Acesso em: 3 jan. 2016.

HESSEL, Ana Maria Di Grado et al. Aprendizagem nas redes sociais virtuais: o potencial da conectividade em dois cenários. Revista eletrônica Contemporaneidade, Educação e Tecnologia [CET], v.1, p.53-60, 2012. Disponível em: http://revistacontemporaneidadeeducacaoetecnologia02.files.wordpress.com/2012/04/ pucsp_2012.pdf; Acesso em: 8 jan. 2016.

LEONTIEV, Alexis. Sobre o desenvolvimento histórico da consciência. In:

O desenvolvimento do psiquismo. Lisboa: Horizonte Universitário, 1978. p.89-142.

LÉVY, Pierre. Educação e cibercultura In: . Cibercultura. São Paulo: Ed. 34, 
1999. p.1-13. Disponível em: http://www.sescsp.org.br/sesc/images/upload/conferencias/29.rtf; Acesso em: 15 jun. 2015.

LOPES, Alice R. C. Conhecimento escolar: ciência e cotidiano. Rio de Janeiro: Eduerj, 1999.

MORAN, José Manuel. Como utilizar a Internet na Educação. Revista Ciência da Informação, v.26, n.2, maio/ago., p.146-153, 1997.

NADAI, Elza. O ensino de história no Brasil: trajetória e perspectivas. Revista Brasileira de História, São Paulo: Anpuh; Marco Zero, v.13, n.25/26, p.143-162, 1993.

RÜSEN, Jörn. Didática da história: passado, presente e perspectivas a partir do caso alemão. Práxis. Educativa, v.1, n.2, p.7-16, 2006. Disponível em: http://www.revistas2.uepg.br/index.php/praxiseducativa/article/view/279/285; Acesso em: 15 ago. 2015.

SCHMIDT, Maria A. M. dos Santos; GARCIA, Tânia M. F. Braga. A formação da consciência histórica de alunos e professores e o cotidiano em aulas de história. Cad. Cedes, Campinas, v.25, n.67, p.297-308, set./dez. 2005. Disponível em: http:// www.scielo.br/pdf/ccedes/v25n67/a03v2567.pdf; Acesso em: 10 set. 2015.

SELWYN, Neil. O uso das TIC na educação e a promoção de inclusão social: uma perspectiva crítica do Reino Unido. Educ. Soc., Campinas, v.29, n.104 - Especial, p.815-850, out. 2008. Disponível em: http://www.scielo.br/scielo.php?script=sci_ arttext\&pid=S0101-73302008000300009\&lng=en\&nrm=iso; Acesso em: 2 jan. 2016.

SILVA, Marco. Sala de aula interativa a educação presencial e à distância em sintonia com a era digital e com a cidadania. In: INTERCOM - Congresso Brasileiro de Comunicação, 24., Campo Grande, MS, 2001. Anais... Disponível em: www.unesp. br/proex/opiniao/np8silva3.pdf; Acesso em: 7 jan. 2016.

TOMAEL, Maria I.; ALCARA, Adriana R.; DI CHIARA, Ivone G. Das redes sociais à inovação. Ci. Inf., Brasília, v.34, n.2, ago. 2005. Disponível em: http://www.scielo. br/scielo.php?script=sci_arttext\&pid=S0100-19652005000200010\&lng=pt\&nrm= iso; Acesso em: 8 jan. 2016.

VIGOTSKI, Lev Semenovitch. Aprendizagem e desenvolvimento intelectual na idade escolar. In: .; LURIA, Alexander R.; LEONTIEV, Alexis N. Linguagem, desenvolvimento e aprendizagem. São Paulo: Ícone, 1998. p.103-117.

. Pensamento e palavra. In: A construção do Pensamento e da Linguagem. São Paulo: Martins Fontes, 2001.

. Psicologia Pedagógica: ed. comentada. Trad. Claudia Schilling. Porto Alegre: Artmed, 2003.

VYGOTSKY, Lev Semenovitch. A formação social da mente: o desenvolvimento dos processos psicológicos superiores. Org. Michael Cole et al. Trad. José Cipolla Ne- 
to, Luis S. Menna Barreto, Solange C. Afeche. 5.ed. São Paulo: Martins Fontes, 1994.

VYGOTSKY, Lev Semenovitch. História del desarrollo de las funciones psíquicas superiores. In: . Obras escogidas. Tomo III. 2.ed. Madrid: Visor, 2000.

\section{NOTAS}

${ }^{1}$ Investigação realizada com professores de História por Joelci Mora Silva para a confecção da monografia "História Regional em uma escola pública de Campo Grande - MS: a voz dos professores", defendida e aprovada no ano de 2008 pelo Departamento de História e Direito da Universidade Federal de Mato Grosso do Sul (UFMS), sob orientação da Profa. Dra. Sônia da Cunha Urt.

${ }^{2}$ Pesquisa para elaboração da dissertação " $\mathrm{O}$ 'internetismo' escolar e os processos educativos: percepções dos professores", que ouviu os professores das redes públicas municipal e estadual, de Campo Grande, MS, de autoria de Joelci Mora Silva sob orientação da Profa. Dra. Sônia da Cunha Urt.

${ }^{3}$ Software desenvolvido por meio de uma parceria entre a Harvard University, o Museu de Belas Artes de Boston e a empresa de software Dassault Systèmes. Foi projetado com base em pesquisas acadêmicas que estudaram documentos históricos e dados arqueológicos e permite uma visita interativa à necrópole de Gizé, no Egito. Tem o Português como um dos idiomas disponíveis. Requer um player 3d. Disponível em: http:// giza3d.3ds.com/br-experience.html? L=br.

Artigo recebido em 23 de setembro de 2015. Aprovado em 20 de dezembro de 2015. 